\title{
The Precarity of Older Adults Living Alone With Cognitive Impairment
}

\author{
Elena Portacolone, MPH, MBA, PhD, ${ }^{1, *}$ Robert L. Rubinstein, PhD, ${ }^{2}$ \\ Kenneth E. Covinsky, MD, MPH, ${ }^{3}$ Jodi Halpern, MD, PhD, ${ }^{4}$ and Julene K. Johnson, PhD ${ }^{1,5}$
}

'Department of Social and Behavioral Sciences, Institute for Health \& Aging, University of California, San Francisco. ${ }^{2}$ Department of Sociology \& Anthropology, University of Maryland, Baltimore County. ${ }^{3}$ Division of Geriatric Medicine, University of California, San Francisc $0 .{ }^{4}$ School of Public Health, University of California, Berkeley. ${ }^{5}$ Department of Medicine, Center for Aging in Diverse Communities, University of California, San Francisco.

*Address correspondence to Elena Portacolone, MPH, MBA, PhD, Institute for Health \& Aging, University of California San Francisco, 3333 California Street, Suite 340, San Francisco, CA 94118. E-mail: elena.portacolone@ucsf.edu

Received: April 7, 2017; Editorial Decision Date: October 24, 2017

Decision Editor: Barbara J. Bowers, PhD

\begin{abstract}
Purpose of the Study: To examine the lived experience of older adults living alone with cognitive impairment to better understand their needs and concerns. Based on our previous work suggesting that older adults living alone often experience a sense of precarity, we were interested in exploring this construct in older adults living alone with a diagnosis of cognitive impairment. The notion of precarity points to the uncertainty deriving from coping with cumulative pressures while trying to preserve a sense of independence.

Design and Methods: This is a qualitative study of 12 adults aged 65 and older living alone with cognitive impairment. Six participants had a diagnosis of Alzheimer's disease; 6 had a diagnosis of mild cognitive impairment. Participants' lived experiences were elicited through 40 ethnographic interviews and participant observation in their homes. Using a qualitative content analysis approach, interview transcripts and fieldnotes were analyzed to identify codes and themes.

Results: Qualitative analysis of transcripts revealed three themes. Theme 1 described the distress stemming from the uncertainty of having cognitive impairment that has an unpredictable course. Theme 2 drew attention to the tendency of participants to feel responsible for managing their cognitive impairment. Theme 3 described the pressures stemming from the lack of appropriate services to support independent living for persons with cognitive impairment.

Implications: These 3 themes all pointed to facets of precarity. Findings also suggest the dearth of programs to support older adults living alone with cognitive impairment and the need to develop novel programs and interventions.
\end{abstract}

Keywords: Alzheimer's disease, Cognition, Dementia, Qualitative analysis: Content analysis, Social services

Living alone in old age is increasingly common. In the United States, the percentage of older adults living alone (also referred to as older "solo dwellers") more than quadrupled since 1900 . In 2014, $26 \%$ of older adults lived alone, representing 12.5 million people (Stepler, 2016). In both north-western and eastern Europe, about half of women aged 60 and older live alone (Jamieson \& Simpson, 2013).
An increase in older adults living alone has also been noted in Japan (Brown et al., 2002), China (Lei, Strauss, Tian, \& Zhao, 2015), and India (Agrawal, 2012). Longer life spans, availability of pensions, population mobility, high divorce rates, as well an increase in unmarried individuals justifies this trend (Klinenberg, 2012; Lei et al., 2015). Along with the responsibilities of managing a household, 
the advantages of solo dwelling include freedom, privacy, and time for self-development. Yet, some challenges are apparent. Older solo dwellers often have fewer financial resources than counterparts living with others, especially women and ethnic/racial minorities (Stepler, 2016). Recent studies also indicate that older solo dwellers are also more likely to relocate into nursing homes (Pimouguet et al., 2016), an often dreaded event.

Our recent investigations underscore the "precarity" of living alone in old age in the United States (Portacolone, 2013); the notion of precarity evokes an intrinsic sense of uncertainty resulting from coping with cumulative pressures while trying to preserve a sense of independence (Portacolone, 2013; Grenier, Looyd, \& Phillipson, 2017). Whereas precarity is a prevalent construct in labor studies, this notion recently emerged in aging studies to illustrate the negative effects of insecure pension plans (Cracium \& Flick, 2016), contingent work (Bohle, Pitts, \& Quinlan, 2010), dementia (Grenier et al., 2017), and living alone (Portacolone, 2013). While the term "precariousness" was first used, precarity is a more appropriate term because it points to differences in experiences that are socially constructed (Butler, 2004).

In an investigation of 47 older solo dwellers conducted by our group, the overarching theme of precarity emerged from the examination of the challenges related to living alone in old age (Portacolone, 2013, 2015). The participants' precarity derived from their need to prove that they can "make" it alone (Portacolone, 2011), at a time in their life when they often needed services that were expensive, limited, or difficult to access. At the same time, they often experienced a decline in their economic and social resources, as well as in their physical abilities.

Building on the assumption that cognitive impairment is likely to exacerbate the precarity of living alone in old age because it may hamper one's ability to manage a household and to navigate the fragmented system of services, our study focused on older adults living alone with cognitive impairment, a sizable population considering that an estimated one-third of older solo dwellers in Canada (Sibley et al., 2002) and in the United States (Amjad, Roth, Samus, Yasar, \& Wolff, 2016) have cognitive impairment. At an international level, comparisons between older solo dwellers with cognitive impairment and counterparts living with others pointed to solo dwellers' higher unmet needs in self-care (Miranda-Castillo, Woods, \& Orrell, 2010), nutrition (Meaney, Croke, \& Kirby, 2005; Miranda-Castillo et al., 2010), and management of medications (Wattmo, Londos, \& Minthon, 2014). Furthermore, solo dwellers with cognitive impairment are more exposed to self-harm (Miranda-Castillo et al., 2010) and they are less likely to receive a diagnosis for their cognitive impairment (Amjad et al., 2016). Informal caregivers, such as family members or adult children, are the people usually nominated as critical providers of care for persons with dementia (WHO, 2012). Yet they may be emotionally or physically distant or unavailable to older solo dwellers with cognitive impairment (Miranda-Castillo et al., 2010; Wattmo et al., 2014). Further, persons with dementia are likely to underreport their needs because of memory problems, lack of insight, or denial (Meaney et al., 2005). Furthermore, an international body of literature (Lian et al., 2017; Mockford et al., 2017; A. Robinson et al., 2009) has recently pointed to the challenges in accessing services for persons with dementia, a system that a British caregiver described as a "terrible maze ... [with] dead ends practically everywhere you turn" (Peel \& Harding, 2014, p. 650).

Despite these alarming findings, primarily from quantitative studies, very little is known about the lived experience of older adults living alone with cognitive impairment. The few qualitative investigations of older adults living alone with cognitive impairment underscored the challenges of using everyday technology (e.g., mobile phones, alarm clocks) among Swedish older solo dwellers (Nygard \& Starkhammar, 2007), the extraordinary efforts reported in a study of older Canadian women with cognitive impairment to avoid making mistakes such as forgetting to lock doors (de Witt, Ploeg, \& Black, 2009), the supportive role of Irish rural communities (Gilmour, Gibson, \& Campbell, 2003), as well as the compromises accepted by study participants in the United States to preserve a sense of independence (Harris, 2006). The objective of this qualitative investigation was to describe the overall experience of older adults living alone with cognitive impairment in order to better understand their priorities, needs, and concerns. To achieve this goal, we used similar methods developed in our previous studies of older adults who live alone (Portacolone, 2013, 2015) and recruited 12 older adults living alone with a medical diagnosis of Alzheimer's disease (AD) or mild cognitive impairment (MCI).

\section{Design and Methods}

Qualitative research methods were selected because of the desire to better understand the subjective nature of the experience of living alone with cognitive impairment. This information is usually gathered via open-ended interviews and participant observation. Furthermore, in qualitative methods, qualitative content analysis of interviews and notes of the observations ("fieldnotes") allows researchers to identify themes (inductive analysis) emerging from the data as well as to assess whether the themes that emerged confirm theoretical constructs (deductive analysis; Elo \& Kyngas, 2008). In this investigation, inductive analysis was used to understand the overall experience of older solo dwellers with cognitive impairment, and deductive analysis was then used to gauge whether study participants were in precarious situations. Qualitative researchers select theoretical frameworks before the analysis when specific frameworks might help them better understand the population studied by offering structures for the inquiry, as well as questions to be addressed (Anfara \& Mertz, 2015; 
Maxwell, 2013; Miles \& Huberman, 2014). In our study, the theoretical framework of precarity was selected before the analysis because of the goal to understand whether precarity would emerge in the investigation as it did in our prior investigation of older solo dwellers. The institutional review board at the University of California, San Francisco approved the study. All the names are pseudonyms and potentially identifying features of participants were omitted or slightly changed.

\section{Participant Eligibility and Recruitment}

Eligibility criteria included: age $\geq 65$ years; a medical diagnosis of $\mathrm{AD}$ or MCI; living alone; and the ability to provide consent. Living alone was defined as living without others. Administrative staff, physicians, and social workers of health care organizations based in Northern California referred potential participants.

\section{Data Collection}

The first author developed the in-depth ethnographic interview protocol, and a co-author (R. L. R.) reviewed it to ensure that the questions were open-ended and elicited information on different elements of participants' lived experience. An in-depth ethnographic interview involves tailoring questions to respondents' trains of thought, seeking detailed explication of each point of experience that is mentioned (Spradley, 2016 [1979]). Specifically, participants were asked about their experiences of living alone, their likes/dislikes, and what resources were essential for them. Participants were asked what they thought about their cognitive function, such as remembering events and finding the right words. If they believed that they had difficulty with cognitive function, they were asked about strategies they employed to cope. The investigator also asked participants what support networks they used, and whether they were satisfied with them. Data from interviews were supplemented with data from participant observation of participants' daily routines. In this mode, researchers use their experiences in relation to the studied population as part of the data (Creswell, 1998). The first author made the observations and took fieldnotes of participants' appearance and body language. To ensure reflexivity, she carefully recorded her reactions to what was observed, as well as her possible bias and role in encounters.

To encourage elaboration on topics related to precarity, attention was placed on four specific topics in observations and narratives, including uncertainty; independence; services; and cumulative pressures. First, study participants were asked to elaborate on statements about feeling a sense of uncertainty, such as "I don't know what to do." Second, attention was placed on statements and cues about the importance of being independent. Third, attention was placed on information indicating that support services were either too expensive, hard to find, unavailable, or inappropriate, as well as to information of any pressures stemming at multiple levels, for example, "That's another exhausting thing [to do]." Interviews were audiotaped and lasted approximately $1.5 \mathrm{~h}$. Home visits lasted approximately $2.5 \mathrm{~h}$. Participants received a $\$ 30$ gift card at the first interview.

\section{Participant Characteristics}

Twelve older adults living alone were visited 40 times (an average of three visits per person) between August 2013 and April 2016. Participants had a mean age of 79 years (range 71-85 years) at the first interview. Six had a diagnosis of AD; six had a diagnosis of MCI. Ten were women. Eleven were non-Latino white and one was Asian. Seven were widowed, three divorced, and two never married. Five participants had a high school level education and seven had a Bachelor's degree or more. Four resided in a building for seniors, the others in conventional housing.

\section{Data Analysis}

Transcripts of audiotaped recordings of interviews and fieldnotes were loaded into Atlas-Ti, a software program for qualitative data analysis. Using a conventional approach to content analysis (Hsieh \& Shannon, 2005), inductive coding was completed. In inductive coding, codes are not created before analyzing the data to allow the codes emerge from transcripts of interviews and fieldnotes. A research assistant experienced in content analysis confirmed the coding results. For example, the code "strategychecking calendar" was assigned to the quote "I'm like a crazy person. I'm checking every time I know something is coming up." Themes were then discovered through the process of connecting codes. Thematic saturation was reached with three themes. Saturation is established when no new types of information or themes are added as new informants come to be interviewed. In the example, because in addition to checking calendars several other strategies to self-manage the cognitive impairment were identified, the theme "self-management of the challenges caused by cognitive impairment" emerged.

Only after the content analysis was completed, the conceptual framework of precarity was applied to the emerging themes. In this deductive portion of the analysis, directed content analysis (Hsieh \& Shannon, 2005) was used to understand if the theoretical construct of precarity was present in the themes, we purposely looked for four markers of precarity in the quotations of each theme. The four markers were: uncertainty about what to do; importance of maintaining independence; limited access to appropriate services; and cumulative pressures. Our criterion was that precarity was present in the theme if at least two out of four markers were consistently identified in the quotations. In 
this second phase of analysis, a colored code was created for each marker. Next, for each theme we examined all quotations to understand if they captured one or more markers of precarity; in doing so we kept into account the overall participants' narrative. For example, for the theme "selfmanaging the cognitive impairment," we re-examined the quotation "I'm like a crazy person. I'm checking every time I know something is coming up." The code "uncertainty" was assigned because this quote speaks of the uncertainty coming from missing appointments. The code "cumulative pressures" was also assigned because the quote points to the pressures of trying to keep abreast of a demanding schedule despite an impaired short-term memory. Also the code "wanting to be independent" was assigned because the study participant relied solely on her initiative; besides, in other quotes, she discussed how important it was to rely on her own initiative. At the end of this process, because each theme contained at least two markers of precarity (Table 1), we concluded that the theoretical construct of precarity was present in each theme, as the Results section will further elucidate. To ensure rigor and validity in qualitative analysis, the first author's reflexivity, that is, her "role, possible bias, and influence on the research and interpretation" (Schoenberg, Miller, \& Pruchno, 2011, p. 283), was essential because of her lead role in data collection and analysis. Fieldnotes and memos collected reflections on the fact that her status of middle-aged solo dweller might have facilitated rapport with study participants. Reflections also kept track of the way the researcher used her lack of cognitive impairment, as well as her pointed questions to have study participants explain what it is like to have a cognitive impairment while living by themselves. To weight the odds for the emergence of the notion of precarity from the data, special attention was placed on negative evidence (Miles
\& Huberman, 2014). Specifically, questions expanded narratives on positive experiences and a sense of support and certainty. Finally, rigor and validity were also ensured with triangulation (data collected through interviews and observations) and respondent validation (researcher explaining to participants what she understood from them).

\section{Results}

\section{The Precarity of Living Alone in Old Age With Cognitive Impairment}

Three themes were identified (Table 1). Each theme pointed to facets of the precarity of older adults living alone with cognitive impairment as elucidated at the end of each subsection. The first theme focused on the distress stemming from the uncertainty of having a cognitive impairment. The second theme was the tendency of participants to feel responsible for managing their impairment on their own. The third theme described the pressures emanating from the lack of appropriate services to support living alone with cognitive impairment.

\section{Theme 1: Awareness of Cognitive Impairment}

All participants sensed and described their difficulties with thinking. They never used the term "cognitive impairment." Instead, they used words such as "condition," "memory loss," "forgetting things," "getting stupid," "Alzheimer's," or "mild cognitive whatever." At times, participants stressed what appeared to them as the strange and elusive nature of their difficulties with thinking. As Ms. Left, 79 shared, "Occasionally I will have a little blackout. And it's something that I know I know, but I can't put it in the right

Table 1. Themes and Subthemes

\begin{tabular}{lll}
\hline Theme & Subtheme & Relation with precarity \\
\hline 1. Awareness of cognitive impairment & Being upset & Uncertainty \\
& $\begin{array}{l}\text { Experiencing random and sudden fluctuations } \\
\text { in cognition }\end{array}$ & Cumulative pressures \\
& Experiencing decreased ability to communicate & \\
& Experiencing decreased ability to organize & \\
& Being concerned about the future & \\
& Feeling relief & Uncertainty \\
& Experiencing feelings of shame or self-stigma & Wanting to be independent \\
& because of the cognitive impairment & Cumulative pressures \\
2. Self-management of the challenges caused & Compensatory strategies & \\
by the cognitive impairment & Strategies to come to terms with the cognitive & Uncertainty \\
& impairment & Loncealing strategies \\
& Feeling exhausted & Cumulative pressures
\end{tabular}


place. That sort of feeling." The random and sudden quality of these cognitive fluctuations was often emphasized, as well as the anxiety, panic, or anger the experience triggered. The first line of a poem that Ms. Oswald, 81, wrote about her cognitive fluctuations reads, "Midway into the sentence. I stop." The next line describes her experience of suddenly forgetting: "Panic for a lost word. I stop." As the poem alludes, most participants often talked about the anxiety or "panic" of not being able to think well on the spot, an experience which fostered a sense of uncertainty in their everyday lives. Participants were particularly concerned about their difficulty with retrieving words and tracking both things and time. "Inside I am on edge," said Ms. Left: this statement is representative of most participants.

Solo dwellers with MCI and a family history of AD were particularly distressed. For example, Ms. Jackson, 73, recalled, "Every time I forget something I would think, 'Oh my God, it's here'." Distress was also observed among solo dwellers whose identities were closely linked with skills that were affected by cognitive impairment. For instance, one participant retired prematurely from his teaching position because he could no longer engage in complex conversations. Another participant, a former executive, was ashamed by her newly developed difficulty with writing. Crying, she said, "People are startled when they know that [I cannot write]." Ms. Reds, 71, a retired manager who prided herself on her outstanding organizational skills questioned herself because of the effort it now took to complete tasks (such as organizing outings) that she had once performed seamlessly. Some participants stressed their confusion. Two participants expressed relief at knowing that they had a cognitive impairment. Ms. Oswald found relief in the prospect that her impairment would erase painful memories. Ms. Well, 80 felt "off the hook" about her forgetfulness after receiving a diagnosis of AD.

Most participants were concerned about the future trajectory of their condition. Generalized slowing was sometimes noted. Mr. Solo, 79, a former scientist, clarified, "I can feel the decline every day in terms of what I am able to do and that I have to slow down." In his words, this slowing can manifest in "goofing around" at home or "living on the couch" watching television. As he summarized, "It's a combination of not remembering anything and everything else is mañana [Spanish for tomorrow]."

\section{Theme 2: Self-Management of the Challenges Caused by Cognitive Impairment}

A second theme focused on the challenges caused by cognitive impairment in the context of living alone. Strategies were often used to compensate for the impairment, to come to terms with it, or to conceal the impairment from others. To compensate for their impairment, participants often resorted to rationality or intuition. With regard to rationality, Mr. Solo quipped, "The only thing I have left is a little bit of logic." Many participants mentioned their need to be more "careful" than in the past to avoid "making mistakes" or to "keep track of things." A common compensatory strategy for disorientation to time was dependence on frequent external cueing, for example, constant checking of calendars or watches. Without a cohabitant, these items seemed essential to navigate the everyday in the context of living alone. Ms. Reds for example explained, "Sometimes I will look at the calendar four, five, six times." To remember appointments she checked both her calendar and wristwatch multiple times. In her words, "I'm like a crazy person. I'm checking every time I know something is coming up." Managing the calendar was sometimes challenging for participants, as this fieldnote about scheduling a third visit with Ms. Jones, 82, attests:

We found that April 21st worked. Ms. Jones wrote the note on her calendar in the bedroom. She asked my first name and my phone number. Then she forgot immediately that she wrote that information in the calendar so she put it in another calendar in the kitchen and she wrote "research" with a question mark. So I said, "My name is Elena, this is my number." Ms. Jones took note and drew a big circle with a smiley face around it. But then, when I said, "Okay, I am going to see you on April $21^{\text {st }}$, she walked back to the calendar in the kitchen with the intention of writing the appointment once again.

Ms. Lewis, 79 called an information telephone number to learn the current date. Ms. Left subscribed to a newspaper. She explained, "I get the newspaper to make sure that I know what day of the week it is. That's the only reason." Before meetings, Mr. Walker, 78, penciled notes and at the meeting, if he forgot the note, he explained, "I just grab the paper and say, 'Oh, here's what I came for, and here's what I'd like to talk about, and good to see you, thank you'." The former scientist, well-versed in technology, relied on Internet search engines. He shared, "I live on Google because I forget everything. I'll often not remember names, but I'll remember an event. So I will just go back on Google and it stops my anxiety."

Other compensatory strategies included taking notes, using sticky notes and organizing topic folders. The toll of taking notes to compensate for a waning short-term memory and the absence of reminders from cohabitants is evident in this quote from Ms. Reds:

I write a ton of notes. I don't remember where I put them and so I have a hard time going back and finding them because I've written a ton of notes ... And the thing about notes, you can carry a little notebook that's like this. You fill the paper up right away. Then you have to have another notebook, and another little notebook, and another little notebook. And I don't want to walk around with a huge book to write all my notes.... But if I'm writing something [laughs] I fill the notebook up in 20 minutes. Well, not quite, but quickly. So it's exhausting. That's another exhausting thing. 
Interestingly, none of the participants expressed disorientation to space, probably because this study took place in their homes.

Participants used strategies to conceal their cognitive impairment from others because they did not want to burden them and because they were embarrassed about it. As Ms. Lewis shared, "I put on a grand show for my grandson." Her show included forced cheerfulness. Ms. Well withheld the news of her diagnosis of $\mathrm{AD}$ from a close friend. She explained, "Everyone has their own set of problems. So why share yours?" Similarly, Ms. Reds stated, "I very intentionally do not want to make my memory issues the topic of conversation." Often, participants refrained from having long interactions with others because they were embarrassed by their difficulty with finding words. For example, at the gym, a former professor preferred solitary workouts with aerobic machines to conversations that were hard for him to follow. About his interactions with men at the gym, he said, "I smile. If somebody laughs, I sort of laugh with a fake laugh." Another strategy was to deflect the attention away from oneself. For example, participants enjoyed attending events without having to do much of the talking. During her interactions with participants, the first author noted that participants often asked her for updates. For example, at the beginning of interviews Ms. Reds asked multiple times, "What is new?" Then, once she was asked questions about the past interview, she explained that she forgot everything she said in the earlier interview and added, "If you were to say, 'Well, one thing we talked about was ...' I would hope that I could grab onto that and maybe remember it." The management of the cognitive impairment often consumed participants. As one participant explained, "Where did I put it?' is the bane of my existence. What did I do with that? Where did I put it?" Some participants found the pressure of trying to manage things so stressful that it led to despair or even suicide.

Participants' intuition also compensated for their declining ability to recall past interactions. For example, two participants opened their door to the researcher, even though they had forgotten their past interactions with her, because they said that they had a good feeling about her. As Ms. Lewis explained, "I hold onto the fact that I liked you." Humor and positive thoughts were strategies they reported as useful to deal with their impairment. A participant smiled and showed the thumbs up when the first author guessed a word that she could not recall. Another participant, a former academic, 83, explained, "I try not to worry because worrying is not a very happy thing to do.” Ms. Well echoed her, as she said, "Take it as it is and live today."

\section{Theme 3: Lacking Tailored Services}

Another theme among participants was the lack of available tailored services for living alone with cognitive impairment. This included a lack of knowledge about services available and the dearth of services meeting their needs.
This topic is pressing to older adults who live alone because they often have to manage their households and their health by themselves. Obtaining a diagnosis of AD or MCI did not necessarily led to appropriate referrals, access, or effective use of social or medical services. For example, a recently widowed and childless woman living alone was "shocked" by the harsh way in which her diagnosis of AD was delivered and subsequent loss of her driver's license. Unable to drive, she sold her house in the countryside because she thought it was too far from public transportation. On her own, she purchased an apartment in a nearby town where she could live without a car. After the relocation, relying mostly on the advice of a neighbor and a receptionist, she tried to understand what services were available to her. Considering her predicament, and pointing to the uncertainty of her situation, she asked, "How am I going to handle things if they get progressively worse?" One year later when her impairment, in fact, had worsened, she said, "I realize how difficult it is for me to manage myself. And I don't know what to do about it." Then she asked, "I don't have good sense of where I'm going, because I don't know where I'm going, you see? ... How much worse is it going to be?" The researcher's inability to answer such questions supplemented by her observation of the progression of the impairment and the limited services available contributed to the emergence of precarity in the findings. Ms. Well, another woman who lost her driver's license following a diagnosis of $\mathrm{AD}$ was less concerned about managing herself because her adult children provided her instrumental support. Yet, she spent most of the time by herself, reporting that she often felt lonely. She said about her time at home, "You slop around in your bathrobe." Her longing to visit local shops and gym was thwarted by the steepness of the street back to her home coupled with her difficulty in learning the local bus system. She reiterated that she would be more active if she had a friend living nearby, but she did not know how to make new friends.

On the other hand, with the exception of Ms. Jade who was satisfied with her private homecare aides and the activities in her building for seniors, older solo dwellers who used social and medical services often reported concerns about their continued ability to use these services as well as the quality of the support.

For instance, Ms. Jackson enjoyed the exercises to train her memory offered by a nearby community center. However, she did not participate in the classes as much as she wanted because they were too expensive. Ms. Jones attended a support group mostly to please her adult child. Ms. Lewis complained about the fiduciary assigned to manage her money by her physician. She said, "I call her brittle ... she talks so fast and her body movements are so quick ... I'm always glad when she leaves." She added, "I will ask her how much money I have in my checking account. She never seems to know." One childless participant tried to quell her "need to talk to somebody" by calling a telephone friendship line without success. She said, "They were not 
very helpful at all... Just very trite in their response.” This participant was also distressed because her social worker reported to Adult Protective Services her plan to sell her house to an acquaintance. Included in the sale was the agreement that she would remain in her house until she died and that the buyer would take care of the maintenance, a task too complex and expensive for her. She was distressed because her acquaintance was accused of taking advantage of her and it was hard for her to take a stand against Adult Protective Services. In her words, "At this point it's like there's too many people, and I don't know who has the power to do what as far as my welfare." She then asked, "Is there somebody that can come along and say 'You can't stay in your house anymore'?"

\section{Discussion}

In this study on the lived experience of older solo dwellers with cognitive impairment, we captured valuable insights about the sense of precarity, or intrinsic uncertainty, that besets study participants. Interviewing participants multiple times, until areas of meaning in their lives were better understood, contributed to the depth of these insights. Using participants' narratives and observations, we illustrate the "cumulative effect," to use the words of a participant, of pressures stemming from the unpredictable and intensifying quality of cognitive impairment, the lack of tailored services for living alone with the impairment, and a need to feel independent, that conspire to create a sense of precarity.

At a personal subjective level, a sense of intrinsic and visceral uncertainty came from the awareness of the cognitive impairment, as well as from its often-unpredictable course. Older adults living alone discussed sudden fluctuations in cognition, which added uncertainty in their everyday lives. They also discussed their decreased abilities to communicate or to organize, slowing, and the worsening of their cognitive function. Reactions to these experiences included anxiety, shame, exhaustion, apathy, and relief. These reactions hampered the ability to thrive alone at home. The construct of precarity manifested in this theme because of the consistent presence of the markers of "uncertainty" and "cumulative pressures" in the narratives. Specifically, a sense of chronic uncertainty was noted in accounts about the unpredictable manifestations of the impairment, as well as by the inability to accurately predict the future course. Cumulative pressures were detected in participants' efforts to cope with the impairment as they tried to keep up with tasks performed when they were cognitively healthy such as organizing trips or attending classes. A unique contribution of this study is its in-depth discussion of insights of elders living alone about their impairment. Participants had varying ways of expressing awareness and insights, much of which would not be identified in a more traditional survey-based study. The characterization of their reactions to difficulties with thinking is distinctive as well considering that only few studies noted the concern of older adults living alone about a worsening of their cognitive functions (de Witt, Ploeg, \& Black, 2010; Duane, Brasher, \& Koch, 2013; Harris, 2006). These investigations echo our findings as they underline the tension between the solo dwellers' desire to remain at home and their increasing difficulties with thinking clearly.

The idea of precarity also emerged from the often-solitary efforts of study participants to manage the everyday practical challenges of living alone with cognitive impairment. These efforts were aligned with the notion that they should be responsible for their own health independently, with little help from others, as well as from institutions (Beck, 1992). Participants used a variety of strategies, mostly on their own, to cope. To compensate for their diminished memory, most participants relied on notes, folders, and the Internet. To compensate for their disorientation to time, participants checked calendars, watches, information lines, and newspapers. The ultimate challenge to them was to retain this information over a period of time without the support of a cohabitant. To conceal their impairment from others, participants altered their communication style, reduced social interactions, and used forced affective states such as conspicuous cheerfulness. Finally, some participants described tapping into their inner strength. Precarity was reflected in this theme mostly through the detection of two markers. First, the marker of "uncertainty" was noted in the analysis of the several strategies to manage the impairment. All strategies pointed to the need to manage the uncertainty of the prospect of forgetting dates, names, scheduled events, or the reasons to attend meetings. Second, the marker "wanting to be independent" was identified in participants' efforts to manage by themselves the impairment, often without wanting to rely on others. Concealing the impairment from others could also be a sign of wanting to be independent. Finally, "cumulative pressures" manifested in the effort of self-managing the impairment while being distressed about it, as well as trying to navigate multiple everyday activities in the context of living alone. A poignant manifestation of these cumulative pressures comes from Ms. Reds' statement about filling notebooks to keep track of events: "That's another exhausting thing [to do]," she said. Her words point to the multiple and "exhausting" additional tasks that study participants had to perform because of their cognitive impairment in the context of living alone.

Other studies of older solo dwellers with cognitive impairment discussed coping strategies (de Witt et al., 2009; Duane et al., 2013; Harris, 2006; Nygard \& Starkhammar, 2007). As with our participants, other studies have reported that older adults living alone with cognitive impairment eschew social interactions to avoid being reminded about their impairment as well as to avoid divulging clues that they might not be able to live alone as easily as in the past (de Witt et al., 2009; Duane et al., 2013; Harris, 2006). For example, a Canadian woman in one study shared, "I 
have seen too many cases where they [members of the social circle] overreact ... so it's a scary process ... to open up" (de Witt et al., 2009, p. 279). Participants in our study describe previously unreported strategies, such as using the Internet, telephone information services, and intuition as coping strategies for orientation and social interaction. It is important to note that our study expands the scant body of published evidence on living alone with cognitive impairment by reporting on strategies devised specifically by solo dwellers. Most prior studies interviewed persons with cognitive impairment who were living with others or their caregivers (L. Robinson et al., 2011; Norton et al., 2009). As a result, the main strategies that emerged were the person's reliance on the live-in caregiver, often a spouse.

Finally, a sense of precarity was heightened by the paucity of services appropriate for older solo dwellers with cognitive impairment, which is one marker of precarity. Many participants did not access, use, or know of services tailored to their specific needs. In particular, this study highlighted a lack of tailored medical, social, financial, and transportation services. This lack of tailored services contributed to the distress of having a cognitive impairment in the context of living alone. Other two markers pointed to the presence of precarity in this last theme. "Uncertainty" was identified in participants often mentioning their not knowing what to do about the future. Finally, "cumulative pressures" was noted in efforts to live alone with cognitive impairment despite interactions with health care providers who were not fully attuned to study participants' concerns. On a related vein, a recent study indicated that treating older adults living alone with cognitive impairment distressed health care professionals because their protocols disagreed with what their patients wanted. In particular, older solo dwellers wanted to remain in their homes, a recurring theme in most studies (de Witt \& Ploeg, 2016; Duane et al., 2013; Harris, 2006), and health care providers were uncomfortable telling someone that they were not capable of making decisions about their living situation (de Witt \& Ploeg, 2016; Duane et al., 2013). Other studies found that older solo dwellers with cognitive impairment often distrusted professionals such as researchers or health care providers (Tierney et al., 2004; Watson, Ryan, Silverberg, Cahan, \& Bernard, 2014). This fear may be well founded, as a number of studies indicate that this population is at high risk for institutionalization (Soto et al., 2015; Wattmo et al., 2014). This study, therefore, contributes to the implication that older adults living alone with cognitive impairment have specific needs and, therefore, require specific services, as other scholars also indicated (Duane et al., 2013; Miranda-Castillo et al., 2010; Soto et al., 2015; Wattmo et al., 2014).

Our study also contributes to the theoretical framework of precarity in aging studies by drawing attention to the interplay between the drive to be independent, the lack of appropriate services to support older solo dwellers with cognitive impairment, and the uncertainty of having a condition that is untreatable, unpredictable, and difficult to manage. As a result, this study extends our previous work to solo dwellers with cognitive impairment and adds to emerging investigations of precarity in aging studies (Cracium \& Flick, 2016; Grenier et al., 2017). With regards to method, a contribution of this study is to point to the feasibility to recruit and interview older solo dwellers with cognitive impairment, which are individuals often understudied because they do not have a caregiver living with them who may involve them in research studies (Watson et al., 2014).

One implication is that social policies could better support older adults living alone with cognitive impairment to continue living in their homes. This is especially important for countries whose health care services are not fully supported by the government, such as the United States. To make this possible, systemic changes are needed. Countries that have already implemented such supportive services can offer insights. For instance in Denmark, after a diagnosis of cognitive impairment, older solo dwellers are consistently offered the support of state-subsidized home care aides specialized in the care of persons with dementia. Adaptations to their homes (e.g., electric ovens, talking calendars) are also offered (Sundhedsstyrelsen, 2017). It is important to draw lessons from such comparisons, which are also an inspiration for efforts to enact an ethics of care and social integration for persons with cognitive impairment (Kontos, Miller, \& Kontos, 2017). A first step toward such integration is the consideration of the perspective of solo dwellers in protocols about their care (Knowles, Lepore, \& Gould, 2016), which mostly rely on professionals' input. The integration of the perspective of older solo dwellers with cognitive impairment is especially important because of evidence of tensions with providers (de Witt \& Ploeg, 2016; Duane et al., 2013; Gilmour et al., 2003). Specifically, solo dwellers in those studies complained about the providers' limited understanding of their priorities. Conversely, providers stressed the challenges to supporting, often with limited resources, patients who often avoided them. The integration of solo dwellers' perspective is also important because of unrealistic demands placed on them by professional guidelines. For example, the guidelines of the Alzheimer Association (2017) invite people living alone with cognitive impairment to "start building their own care team," a task which is often too difficult for them. To relieve the burden of self-managing their cognitive impairment, affordable or subsidized person-centered services should be provided upon diagnosis of cognitive impairment to people living alone and they could include tailored reminders for medical appointments, ad hoc transportation, and specialized home care aides. Additional research is needed to better understand the specific solutions to address the issues raised in the current study. Studies that include older adults from more diverse racial/ethnic backgrounds are also needed.

\section{Limitations}

This study had three limitations. First, the small size of the sample limited the generalizability of the findings and did not allow the comparison of participants with MCI with 
those with AD. Second, most participants were non-Latino white women. Third, the limited geographical scope comprised a specific locale culturally.

\section{Conclusion}

"The ground on which our life prospects are presumed to rest is admittedly shaky," Zygmunt Bauman (2007, p. 10) wrote, as he proclaimed the beginning of a global "age of uncertainty." Our study suggests that the ground under the feet of older adults living alone with cognitive impairment is shaky, indeed. The vulnerability from the cognitive impairment and the lack of appropriate supportive services to allow them to remain in their own homes jeopardize the sense of independence they clearly desire.

Findings from this study generated a series of questions: How do we alleviate psychological distress in older adults living alone with cognitive impairment? How can we support these persons so that they can stay in their homes? What services would improve their quality of life? How do we tailor these services to their degree of cognitive impairment, particularly as abilities decline over time? How can these services also be tailored to the diverse needs of solo dwellers from different ethnic/racial backgrounds, residence in rural or urban areas, or other traits? Given the considerable numbers of older solo dwellers with cognitive impairment in North America (Amjad et al., 2016; Sibley et al., 2002) and likely elsewhere, it is critical to answer these questions.

\section{Funding}

This work was supported by the Career Development Award (EP K01AG049102) from the National Institute on Aging, National Institutes of Health, by the New Investigator Research Award from the Alzheimer Association (NIRG-15-362325), and by the Pepper Center at UCSF (P30AG044281), which promotes promising new research aimed at better understanding and addressing late-life disability in vulnerable populations. The UCSF Center for Aging in Diverse Communities (P30AG15272) and the Resource Allocation Program also supported this work.

\section{Conflict of Interest}

The authors have no conflict of interest to report.

\section{Acknowledgments}

The authors wish to express their gratitude to all study participants and academic and community partners, as well as to the two anonymous reviewers. A special thank you goes to the reviewers of the Works-in-Progress seminar at the Clinical and Translational Science Institute at the University of California in San Francisco (UCSF), and to the editor Amy J. Markowitz, JD. No funding source had any role in the study design; collection, analysis, or interpretation of data; writing of the report; or the decision to submit the article for publication. The content is solely the responsibility of the authors and does not necessarily represent the official views of the National Institutes of Health, the Alzheimer Association, or the University of California.

\section{References}

Agrawal, S. (2012). Effect of living arrangement on the health status of elderly in India: Findings from a national cross sectional survey. Asian Population Studies, 8, 87-101. doi:10.1080/1744 1730.2012.646842

Alzheimer's Association. (2017). If you live alone. Retrieved June 2, 2017 from http://www.alz.org/i-have-alz/if-you-live-alone.asp

Amjad, H., Roth, D. L., Samus, Q. M., Yasar, S., \& Wolff, J. L. (2016). Potentially unsafe activities and living conditions of older adults with dementia. Journal of the American Geriatrics Society, 64, 1223-1232. doi:10.1111/jgs.14164

Anfara, V. A., \& Mertz, N. T. (2015). Theoretical frameworks in qualitative research. Los Angeles: Sage.

Bauman, Z. (2007). Liquid times. Cambridge: Polity Press.

Beck, U. (1992). Risk society. London: Sage.

Bohle, P., Pitts, C., \& Quinlan, M. (2010). Time to call it quits? The safety and health of older workers. International Journal of Health Services: Planning, Administration, Evaluation, 40, 23-41. doi:10.2190/HS.40.1.b

Brown, J. W., Liang, J., Krause, N., Akiyama, H., Sugisawa, H., \& Fukaya, T. (2002). Transitions in living arrangements among elders in Japan: Does health make a difference? The Journal of Gerontology, Series B: Psychological Sciences and Social Sciences, 57, S209-S220.

Butler, J. (2004). Precarious life. London: Verso.

Craciun, C., \& Flick, U. (2016). Aging in precarious times: Exploring the role of gender in shaping views on aging. Journal of Women \& Aging, 28, 530-539. doi:10.1080/08952841.2016.1223896

Creswell, J. (1998). Qualitative inquiry and research design: Choosing among five traditions. Thousand Oaks: Sage.

de Witt, L., \& Ploeg, J. (2016). Caring for older people living alone with dementia: Healthcare professionals' experiences. Dementia (London, England), 15, 221-238. doi:10.1177/1471301214523280

de Witt, L., Ploeg, J., \& Black, M. (2009). Living on the threshold: The spatial experience of living alone with dementia. Dementia, 8, 263-291. doi:10.1177/1471301209103273

de Witt, L., Ploeg, J., \& Black, M. (2010). Living alone with dementia: An interpretive phenomenological study with older women. Journal of Advanced Nursing, 66, 1698-1707. doi:10.1111/j.1365-2648.2010.05295.x

Duane, F., Brasher, K., \& Koch, S. (2013). Living alone with dementia. Dementia (London, England), 12, 123-136. doi:10.1177/1471301211420331

Elo, S., \& Kyngäs, H. (2008). The qualitative content analysis process. Journal of Advanced Nursing, 62, 107-115. doi:10.1111/j.1365-2648.2007.04569.x

Grenier, A. M., Looyd, L., \& Phillipson, C. (2017). Precarity in late life: Rethinking dementia as a frail old age. Sociology of Health \& Illness, 39, 318-330. doi:10.1111/1467-9566.12476

Harris, P. (2006). The experience of living alone with early stage Alzheimer's disease: What are the person's concerns? Alzheimer's Care Quarterly, 7, 84-94. 
Gilmour, H., Gibson, F., \& Campbell, J. (2003). Living alone with dementia: A case study approach to understanding risk. Dementia, 2, 403-420. doi:10.1177/14713012030023008

Hsieh, H. F., \& Shannon, S. E. (2005). Three approaches to qualitative content analysis. Qualitative Health Research, 15, $1277-$ 1288. doi:10.1177/1049732305276687

Jamieson, L., \& Simpson, R. (2013). Living alone: Globalization, identity, and belonging. Basingstoke: Palgrave MacMillan.

Klinenberg, E. (2012). Going solo. New York: Penguin Press.

Knowles, M., Lepore, M., \& Gould, E. (2016). Providing services to individuals with dementia who live alone. Washington, DC: Administration for Community Living.

Kontos, P., Miller, K. L., \& Kontos, A. P. (2017). Relational citizenship: Supporting embodied selfhood and relationality in dementia care. Sociology of Health \& Illness, 39, 182-198. doi:10.1111/1467-9566.12453

Lei, X., Strauss, J., Tian, M., \& Zhao, Y. (2015). Living arrangements of the elderly in China: Evidence from the CHARLS national baseline. China Economic Journal, 8, 191-214. doi:10.1080/17 538963.2015.1102473

Lian, Y., Xiao, L. D., Zeng, F., Wu, X., Wang, Z., \& Ren, H. (2017). The experiences of people with dementia and their caregivers in dementia diagnosis. Journal of Alzheimer's Disease, 59, 12031211. doi:10.3233/JAD-170370

Maxwell, J. (2013). Qualitative research design. Thousand Oaks: Sage.

Meaney, A. M., Croke, M., \& Kirby, M. (2005). Needs assessment in dementia. International Journal of Geriatric Psychiatry, 20, 322-329. doi:10.1002/gps.1284

Miles, M. B., \& Huberman, M. A. (2014). Qualitative data analysis: A methods sourcebook. Thousand Oaks: Sage.

Miranda-Castillo, C., Woods, B., \& Orrell, M. (2010). People with dementia living alone: What are their needs and what kind of support are they receiving? International Psychogeriatrics, 10, 1-11. doi:10.1017/S104161021000013X

Mockford, C., Seers, K., Murray, M., Oyebode, J., Clarke, R., Staniszewska, S., ... Sharma, U. (2017). The development of service user-led recommendations for health and social care services on leaving hospital with memory loss or dementia-The SHARED study. Health Expectations, 20, 495-507. doi:10.1111/hex.12477

Norton, M. C., Piercy, K. W., Rabins, P. V., Green, R. C., Breitner, J. C., Ostbye, T., ... Tschanz, J. T. (2009). Caregiver-recipient closeness and symptom progression in Alzheimer disease. The Cache County Dementia Progression Study. The Journal of Gerontology, Series B: Psychological Sciences and Social Sciences, 64, 560-568. doi:10.1093/geronb/gbp052

Nygård, L., \& Starkhammar, S. (2007). The use of everyday technology by people with dementia living alone: Mapping out the difficulties. Aging of Mental Health, 11, 144-155. doi:10.1080/13607860600844168

Peel, E., \& Harding, R. (2014). 'It's a huge maze, the system, it's a terrible maze': Dementia carers' constructions of navigating health and social care services. Dementia (London, England), 13, 642-661. doi:10.1177/1471301213480514

Pimouguet, C., Rizzuto, D., Schön, P., Shakersain, B., Angleman, S., Lagergren, M., ... Xu, W. (2016). Impact of living alone on institutionalization and mortality: A population-based longitudinal study. European Journal of Public Health, 26, 182-187. doi:10.1093/eurpub/ckv052

Portacolone, E. (2011). The myth of independence for older Americans living alone in the Bay Area of San Francisco: A critical reflection. Ageing \& Society, 27, 166-174. doi:10.1016/j. jaging.2013.01.001

Portacolone, E. (2013). The notion of precariousness among older adults living alone in the U.S. Journal of Aging Studies, 27, 166174. doi:10.1016/j.jaging.2013.01.001

Portacolone, E. (2015). Older Americans living alone: The influence of resources and intergenerational integration on inequality. Journal of Contemporary Ethnography, 44, 280-305. doi:10.1177/0891241614528709

Robinson, A., Elder, J., Emden, C., Lea, E., Turner, P., \& Vickers, J. (2009). Information pathways into dementia care services. Dementia, 8, 17-37. doi:10.1177/1471301208099051

Robinson, L., Gemski, A., Abley, C., Bond, J., Keady, J., Campbell, S., ... Manthorpe, J. (2011). The transition to dementia-individual and family experiences of receiving a diagnosis: A review. International Psychogeriatrics, 23, 1026-1043. doi:10.1017/ S1041610210002437

Schoenberg, N. E., Miller, E. A., \& Pruchno, R. (2011). The qualitative portfolio at The Gerontologist: Strong and getting stronger. The Gerontologist, 51, 281-284. doi:10.1093/geront/gnr032

Sibley, A., MacKnight, C., Rockwood, K., Fisk, J., Gauthier, S., Guzman, D. A., ... Hogan, D. B.; Consortium to Investigate Vascular Impairment of Cognition. (2002). The effect of the living situation on the severity of dementia at diagnosis. Dementia and Geriatric Cognitive Disorders, 13, 40-45. doi:10.1159/000048632

Soto, M., Andrieu, S., Gares, V., Cesari, M., Gillette-Guyonnet, S., Cantet, C., ... Nourhashémi, F. (2015). Living alone with Alzheimer's disease and the risk of adverse outcomes: Results from the plan de soin et d'Aide dans la maladie d'Alzheimer study. Journal of the American Geriatrics Society, 63, 651-658. doi:10.1111/jgs.13347

Spradley, J. P. (2016 [1979]). The ethnographic interview. Belmont: Wadsworth.

Stepler, R. (2016). Smaller share of women 65 and over are living alone. Washington, DC: Pew Center.

Sundhedsstyrelsen. (2017). Sundhedsstyrelsen. Retrieved on June 2, 2017, from https://www.sst.dk

Tierney, M. C., Charles, J., Naglie, G., Jaglal, S., Kiss, A., \& Fisher, R. H. (2004). Risk factors for harm in cognitively impaired seniors who live alone: A prospective study. Journal of the American Geriatrics Society, 52, 1435-1441. doi:10.1111/j.0002-8614.2004.52404.x

Watson, J. L., Ryan, L., Silverberg, N., Cahan, V., \& Bernard, M. A. (2014). Obstacles and opportunities in Alzheimer's clinical trial recruitment. Health Affairs (Project Hope), 33, 574-579. doi:10.1377/hlthaff.2013.1314

Wattmo, C., Londos, E., \& Minthon, L. (2014). Solitary living in Alzheimer's disease over 3 years: Association between cognitive and functional impairment and community-based services. Clinical Interventions in Aging, 9, 1951-1962. doi:10.2147/CIA.S71709 WHO. (2012). Dementia: A public health priority. Geneva: WHO. 